\title{
GruPo TRANSDISCIPLINAR DE ESTUdOS E TRATAMENTO DO ALCOOLISMO E OUTRAS DEPENDÊNCIAS ${ }^{\star}$
}

\author{
Hugo Leonardo Rodrigues Soares $\star \star$ \\ Hérica Cristina Batista Gonçalves $\star \star \star$

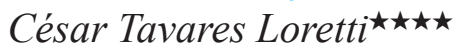 \\ Jairo Werner Junior $\star \star \star \star \star ~$
}

\section{Palavras-chave: dependência química; equipe multidisciplinar; epidemiologia.}

Introdução: O projeto GEAL - Grupo Transdisciplinar de Estudos e Tratamento de Alcoolismo e Outras Dependências se insere num campo cuja problemática ocupa importante espaço do ponto de vista de vista de saúde pública nacional e onde a Universidade, dentro de suas atribuições e compromisso social, deve ter papel preponderante. Nesse sentido, a UFF não poderia continuar omissa diante de um quadro social e médico tão grave. O GEAL- Grupo Transdisciplinar de Estudos e Tratamento do Alcoolismo e Outras Dependências foi fundado em 1994, por iniciativa da Disciplina de Gastroenterologia do Departamento de Medicina Clínica da Faculdade de Medicina da Universidade Federal Fluminense, em atenção à demanda dos pacientes com doença hepática alcoólica face à dificuldade dos mesmos em atingirem e manterem a abstinência e conseqüente agravamento do quadro clínico com a manutenção do consumo de álcool. Mais tarde, as atividades do GEAL envolveram outras dependências, com maior abrangência da sua clientela, fato que motivou a inserção da Disciplina de Neuropsiquiatria Infantil do Departamento Materno-Infantil no seu conjunto. O GEAL é fruto da junção da experiência acadêmica e técnica de alguns professores da UFF com a necessidade da população de Niterói, São Gonçalo e de outros municípios. O GEAL é também o primeiro projeto da área docente da UFF, envolvendo ensino, pesquisa e extensão, voltado para o enfrentamento das importantes questões médicas, psicológi-

$\star$ Trabalho apresentado na $29^{\text {a }}$ Semana Científica da Faculdade de Medicina da UFF, realizada em 30 de novembro e 1 de dezembro de 2006, no Hospital Universitário Antônio Pedro, Niterói, Rio de Janeiro.

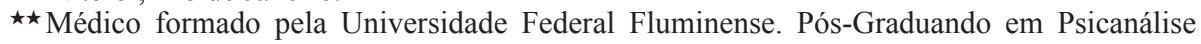
e Saúde Mental pela UERJ. Ex-monitor das disciplinas de Neuropsiquiatria Infantil e Desenvolvimento Infantil. Especialista em Dependência Química pela UNIFESP/EPM. PòsGraduado (lato sensu) Políticas, Instituições e Saúde Mental e Vigilância Sanitária. Fiocruz/ Ensp.E-mail: hugolrsoares@yahoo.com.br

$\star \star \star$ Psicóloga, residente em Saúde Mental do Instituto Municipal Philippe Pinel. E-mail: hericacris@yahoo.com.br

$\star \star \star \star$ Professor de Gastroenterologia do Departamento de Medicina Clínica da Faculdade de Medicina do Centro de Ciências Médicas da UFF. Endereço: Departamento de Medicina Clínica - Faculdade de Medicina - Hospital Universitário Antônio Pedro (HUAP) - Rua Marquês do Paraná, 303, Centro, Niterói - RJ, CEP 24303-900.

$\star \star \star \star \star$ Orientador e professor adjunto IV, responsável pela área de Psiquiatria da Infância e Adolescência da Faculdade de Medicina (Departamento Materno Infantil) do Centro de Ciências Médicas da UFF. Médico e Doutor em Saúde Mental -UNICAMP e Mestre em Educação - UFF. Endereço: Departamento Materno-Infantil - Faculdade de Medicina - Hospital Universitário Antônio Pedro (HUAP) - Rua Marquês do Paraná, 303, Centro, Niterói - RJ, CEP 24303-900.E-mail: jairowerner@globo.com 
cas e sociais da dependência às substâncias psicoativas. Objetivos: Atualização de conhecimentos na área do alcoolismo e outras dependências, para os integrantes do GEAL; Integração com as atividades práticas do curso de graduação e pós-graduação, supervisão de internos, bolsistas e alunos de graduação; Disseminação de conhecimentos advindos do trabalho desenvolvido; Intercâmbio de conhecimentos entre os diferentes setores do GEAL, bem como com outros grupos e instituições. Metodologia: As atividades e ações são desenvolvidas, partindose de uma visão teórico metodológica que considera que o alcoolismo e as outras dependências devem ser consideradas como produto de uma interação sujeito versus drogas, mediado por um processo sócio-cultural. Em relação à pesquisa, o GEAL permite o desenvolvimento de projetos de pesquisa, iniciação científica para alunos de graduação, segundo a área de interesse e as linhas de Epidemologia e Pesquisa Clínica nas áreas de dependência alcoólica, dependência à cocaína e dependência ao cannabis. Nesse contexto, insere-se a documentação e o Banco de dados do GEAL, visando produzir e fornecer orientação para todos os participantes do grupo (bibliografia, dados epidemiológicos, pesquisas já realizadas, etc. Resultados, discussão e conclusões: Existe uma alta prevalência de transtornos psiquiátricos adicionais entre pessoas que buscam tratamento para a dependência de álcool. maconha e cocaína, que é repetidamente confirmada. Sendo assim $75 \%$ dos homens e $65 \%$ das mulheres possuem um diagnóstico psiquiátrico comórbido. $60 \%$ dos pacientes que procuram o GEAL são alcoolistas, cerca de $20 \%$ são usuários de maconha, $15 \%$ utilizam ou foram usuários de outras drogas (solventes, "loló" etc) e 5\% usuários de cocaína. As principais comorbidades são a depressão maior, a distimia, o transtorno obsessivo-compulsivo, transtorno afetivo bipolar, esquizofrenia e transtorno do pânico. 